\title{
1 Identification of a filamentous form of kunitz protease inhibitor in Asteraceae
}

2 Sara Bratsch ${ }^{1}$, Neil Olszewski ${ }^{2}$, Benham Lockhart ${ }^{1}$

$3{ }^{1}$ Department of Plant Pathology, University of Minnesota, Saint Paul MN, 55113, USA

$4{ }^{2}$ Department of Plant and Microbial Biology, University of Minnesota, Saint Paul MN, 55113, 5 USA

SAB ORCID iD: 0000-0002-9678-1651

NEO ORCID iD: 0000-0001-5393-7743

BEL ORCID iD: 0000-0003-0731-6748

Abstract

Filamentous structures were observed in purified extracts from chrysanthemum, gerbera, sunflower and zinnia. When purified filament proteins were subjected to SDS-PAGE, the major protein associated with filaments from all three species has an apparent molecular mass of $\approx 25$ $\mathrm{kDa}$. Protein bands from chrysanthemum, gerbera, and zinnia were subjected to N-terminal protein sequencing while proteins from sunflower were sequenced by CID MS/MS. All of the sequences shared highest similarity to the kunitz trypsin inhibitor family. The sequencing results indicated that the proteins lacked the signal sequences. We tested the gerbera filament protein for glycosylation and found that it was a glycoprotein. Together these results indicate that the filaments are composed of mature KTI protein. This is the first report of a KTI assembling into filaments and the first report of a filament forming Asteraceae enzyme.

Keywords (4-6)

24 Protease inhibitor, kunitz, aster, protein sequencing

\section{Introduction}

The Asteraceae family is one of the largest families of flowering plants belonging to the Angiospermae group (Jeffrey 2007). The Asteraceae group name comes from the type genus Aster, Greek for star, and is referring to the star-like flowers of the family. The Asteraceae family is natively found throughout the world in all habitats except Antarctica and the extreme Arctic. Economically important members include the sunflower, Helianthus annuus, used for trans-fat free oil and a whole seed crop; pyrethrum, Chrysanthemum cineariifolium and $C$. coccineum, from which the natural insecticide pyrethrin is extracted (Casida 1980); stevia, Stevia rebaudiana, a low calorie sweetener (Brandle et al 1998); lettuce, Lactuca sativa, a leafy vegetable; Jerusalem artichoke or sunchoke, H. tuberosus, a tuberous root vegetable; and others. 
Numerous genera are used horticulturally for cut flowers and ornamental plants like the chrysanthemum, Chrysanthemum spp.; coneflower, Echinaceae spp.; dahlia, Dahlia spp.; gerbera daisy, Gerbera spp.; pot marigold, Calendula offinalis; sunflower, Helianthus spp.; and zinnia, Zinnia spp.

Here we report the discovery of proteinaceous filaments in several members of the Asteraceae. In addition to cytoskeleton enzymes such as actin and tubulin, over 100 enzymes that self-assemble into filaments have been identified in both the Prokaryota and the Eukaryota (Park and Horton, 2019). These filaments can have different structures and in some cases a single enzyme can form filaments with different structures. While much remains to be learned about these filaments it is known that assembly into a filament can alter enzymatic activity. Enzyme filaments were first observed in plants by electron microscopy in 1965 (Gunning, 1965). These filaments are composed of $\beta$-glucosidase. In plants three enzymes including $\beta$-glucosidase, ribonucleotide reductase, and IRE1 have been identified forming filamentous structures (Park \& Horton 2019).

Kunitz soybean trypsin inhibitor (KTI) proteins are widely distributed throughout plants and are often encoded by large gene families ranging in size from two to more than 50 genes (Fischer et al 2015; Islam et al 2015). KTIs are plant storage proteins with various functions that can be found in both seeds and vegetative tissues (de Souza Cândido et al. 2011). These proteins are produced at the cytoplasmic surface of the rough endoplasmic reticulum (de Souza Cândido et al. 2011). Most KTIs have an N-terminal signal sequence which directs the proteins into the ER and ultimately deposited in storage vacuoles. During this process the signal peptide is removed and the protein is glycosylated (Muntz 1998, Ee et al. 2011). KTIs collectively inhibit a wide range of proteolytic enzymes (Fischer et al 2015; Heibges et al 2003; Major \& Constabel 2008). In addition, some KTIs have invertase inhibitory activity (Glaczinski et al 2002). Expression of KTIs can be constitutive or induced by herbivory, wounding, pathogens, abiotic stresses and plant hormones (Kang et al 2002; Kim et al 2003; Li et al 2008). KTIs can protect plants from herbivory, pathogens, and some KTIs have a role in plant development, since reducing their expression affects leaf shape, shoot growth and root growth (Islam et al 2015; Li et al 2008).

Here we report the identification and characterization of novel filamentous structures in members of the family Asteraceae including: chrysanthemum (Chrysanthemum sp.), coneflower (Echinaceae spp.), gerbera (Gerbera jamesonii, G. hybrida), sunflower (Helianthus anuus), and zinnia (Zinnia hybrida). Two different protein sequencing methods revealed that these filamentous structures were composed of a protein belonging to the soybean kunitz trypsin inhibitor family.

\section{Materials and methods}

\section{$73 \quad$ Filament Purification}

Filaments were purified for characterization by transmission electron microscopy from chrysanthemum (Chrysanthemum spp.), coneflower (Echinacea spp.), gerbera (Gerbera was frozen in liquid nitrogen, ground with a mortar and pestle, and mixed with $15 \mathrm{~mL}$ of 
$\mathrm{NaN}_{3}, 0.5 \%$ (v/v) 2-mercaptoethanol $\mathrm{pH}$ 7.5). This mixture was filtered using polyester fabric and centrifuged at $19,800 \mathrm{~g}_{\max }$ for $15 \mathrm{~min}$ at $10^{\circ} \mathrm{C}$. The supernatant was removed and mixed with one $\mathrm{mL}$ of $25 \%(\mathrm{v} / \mathrm{v})$ Triton X-100 by vortexing which was layered over five $\mathrm{mL}$ of $30 \%(\mathrm{w} / \mathrm{v}$ ) sucrose in $100 \mathrm{mM} \mathrm{NaPO}_{4} \mathrm{pH} 7.5$ and subsequently centrifuged at 109,000 $\mathrm{g}_{\max }$ for 2 hours at $10^{\circ} \mathrm{C}$. The supernatant was discarded. The pellet was suspended with $100 \mu \mathrm{L}$ of $100 \mathrm{mM} \mathrm{NaPO}_{4}$ $\mathrm{pH}$ 7.5. The solution was emulsified by vortexing with $100 \mu \mathrm{L}$ chloroform and $20 \mu \mathrm{L} 25 \%$ Triton X-100 and was centrifuged for 10 minutes at 26,400 $\mathrm{g}_{\max }$ at room temperature (RT). The upper aqueous phase was used for TEM examination.

Filament preparations used to determine the identity of the filament proteins were further purified by cesium chloride isopycnic density-gradient centrifugation. The aqueous upper phase from above was applied to a preformed $0-30 \%$ cesium chloride gradient with $10 \%(\mathrm{w} / \mathrm{w})$ sucrose in $100 \mathrm{mM} \mathrm{NaPO}_{4} \mathrm{pH}$ 7.0. The gradient was centrifuged for 4.5 hours at $116,000 \mathrm{~g}_{\max }$ at $10^{\circ} \mathrm{C}$. The gradient was fractioned into $500 \mu \mathrm{L}$ fractions. Each fraction was examined by TEM as described below and fractions containing highly enriched filaments were pooled. The pooled fractions were diluted four-fold with $100 \mathrm{mM} \mathrm{NaPO}_{4} \mathrm{pH} 7.5$, and concentrated by centrifuging at $136,000 g_{\max }$ for 2 hours. The pellet was resuspended in $100 \mathrm{mM} \mathrm{NaPO}_{4}, \mathrm{pH} \mathrm{7.5,} \mathrm{containing}$ $0.5 \%(\mathrm{v} / \mathrm{v}) 2$-mercaptoethanol and examined by TEM as described below.

\section{Electron Microscopy}

Two $\mu \mathrm{L}$ of the sample was mounted onto $0.25 \%$ Formvar and carbon coated 200 mesh copper grids (Electron Microscopy Sciences, USA). The grids were examined using a Phillips CM12 transmission electron microscope (University Imaging Centers, University of Minnesota)

102

103 after negative staining with $2 \%$ (w/v) sodium phosphotungstate (PTA), $\mathrm{pH} 7.0$, containing bacitracin at $100 \mu \mathrm{g} / \mathrm{ml}$. The average diameter of filaments was calculated by measuring 50 particles each from coneflower, gerbera, pyrethrum, sunflower, and zinnia using Fiji (Schindelin et al. 2012).

\section{SDS-PAGE}

Purified filaments were resuspended in SDS-PAGE sample buffer and filament proteins were subjected to SDS-PAGE on 4-20\% TruPAGE Precast Gels (Sigma-Aldrich, USA). Gels were stained with Coomassie brilliant blue G-250 stain (Sigma-Aldrich, USA).

\section{Staining of glycoproteins}

Filaments extracted from gerbera were subjected to SDS-PAGE and then the Pierce ${ }^{\mathrm{TM}}$ Glycoprotein Staining Kit (ThermoFisher Scientific, USA) was used as directed. To visualize nonglycosylated proteins the gel was also stained with Coomassie brilliant blue. 


\section{N-terminal protein sequencing}

$\mathrm{N}$-terminal protein sequencing was performed by the Protein Facility of the Iowa State University Office of Biotechnology. Purified filament samples were submitted for analysis. For analysis the proteins were separated on SDS-PAGE and transferred to polyvinylidene difluoride membrane (PVDF). The membrane was stained with Coomassie brilliant blue R-250: 40\% methanol: $10 \%$ acetic acid for 5 minutes and destained. Detectable protein bands were excised for sequencing. Samples were sequenced by Edman Degradation using a Perkin Elmer 494 Procise Protein/Peptide Sequencer with an on-line 140C PTH Amino Acid Analyzer (Applied

126 Biosystems, Inc).

\section{Cloning and sequencing the sunflower kunitz protease inhibitor gene}

The N-terminal sequence from chrysanthemum was used for a tBlastn search of the NCBI EST database. This search identified chrysanthemum EST sequence DK939406.1 but the sequence did not cover the entire coding region. The EST was used as a starting point to assemble a putative sequence of the coding region from other sequences in the NCBI database. Two primers, sunflower_KTI_F (5'-ATGAAGATCACATTGTCTTTCATTTTCTTA -3') and sunflower_KTI_R (5' - CTACTCAGATTGAACAGAAGCCAC- 3'were designed and used in a PCR reaction with total DNA extracted (DNeasy Plant Mini Kit, Qiagen, Valencia CA USA) from sunflower leaf tissue. The PCR reaction was performed using Platinum SuperFi DNA Polymerase I (ThermoFisher Scientific, USA) and a cycling program of $95^{\circ} \mathrm{C}$ for 5 minutes followed by 25 cycles of $95{ }^{\circ} \mathrm{C}$ for 30 seconds, $60{ }^{\circ} \mathrm{C}$ for 30 seconds, $72{ }^{\circ} \mathrm{C}$ for 30 seconds, with a final extension at $95^{\circ} \mathrm{C}$ for 10 minutes. The PCR product was purified (Pure link Quick PCR purification kit, Invitrogen USA), cloned and both strands were sequenced (UMGC, St. Paul USA).

\section{CID MS/MS sequencing}

Proteins associated with purified sunflower filaments were submitted to the Center for Mass Spectrometry \& Proteomics (CMSP) Facility (University of Minnesota) for peptide sequencing by mass spectrometry. Briefly, the purified filaments were denatured and analyzed by SDS-PAGE using Criterion ${ }^{\mathrm{TM}}$ Precast Gels (Bio-Rad). The gel was stained with Imperial Protein Stain (ThermoFisher Scientific). Protein bands of interest were excised to prepare for sequencing and destained (Drbal et al 2001). Proteolytic digestion was completed on the excised protein bands by in-gel trypsin digest using a protocol adapted from Shevchenko et al (1996). The samples were then desalted by STop And Go Extraction (STAGE) TIPS desalting procedure (Rappsilber \& Mann, 2003). Mass spectrometry (MS) was completed as described in LinMoshier et al (2013).

Peaks Studio 6.0 build 20120620 (Bioinformatics Solutions Inc.) software package was used for interpretation of tandem MS and protein inference (Ma et al 2003). Search parameters 
155 included UniProt database (Campanula genera taxonomy ID 91882, accessed Jan 6 2016)

156 concatenated with the common lab contaminants (cRAP) database

157 (http://www.thegpm.org/crap/) and the translated KTI coding region obtained by PCR. In

158 addition, an artificial proteome was created by taking the sunflower transcriptome assembled by

159 Trinity (https://www.sunflowergenome.org/transcriptome.html) and translating it. This artificial

160 proteome was also used in the search parameters. The remaining search parameters for Peaks

161 were followed as described in Dahlin et al (2015).

\section{Results}

Filaments extracted from chrysanthemum (Chrysanthemum spp.), coneflower (Echinacea spp.), gerbera (Gerbera jamesonii, G. hybrida), sunflower (Helianthus annuus), and zinnia

166 (Zinnia hybrida) leaf tissue are shown in Figure 1. The filaments had mean diameters ranging 167 from 7.6 to $8.9 \mathrm{~nm}$ (Table 1) with a mean across all species of $8.5 \mathrm{~nm}$ and variable length 168 ranging up to several thousand $\mathrm{nm}$.

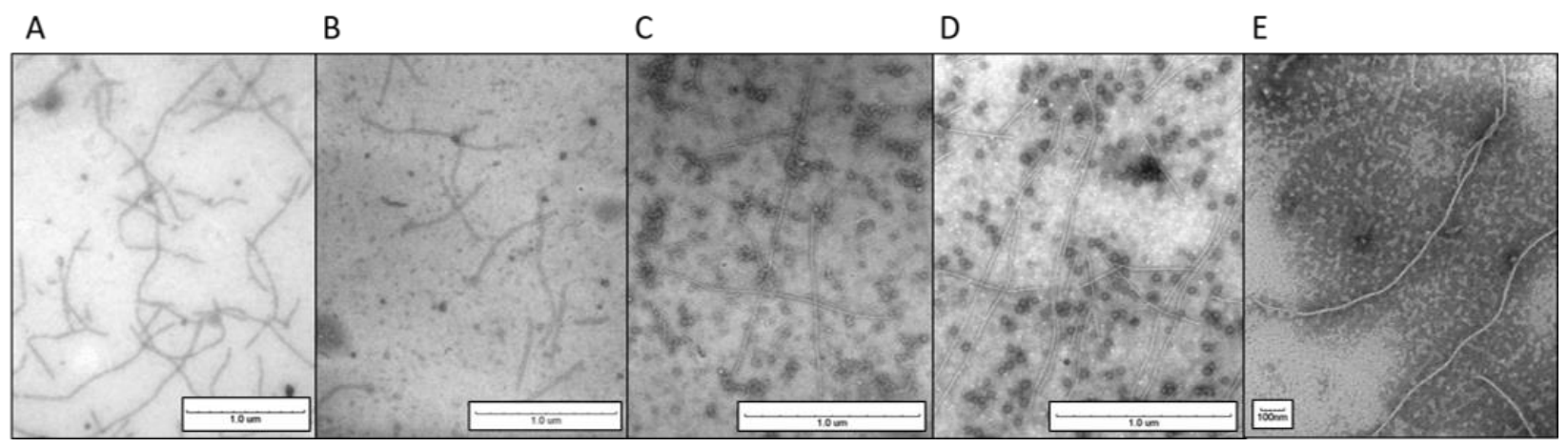

170 Figure 1. Transmission electron micrographs of filaments from A, sunflower $(25,000 \mathrm{X})$; B, 171 coneflower $(31,000 \mathrm{X})$; C, chrysanthemum $(40,000 \mathrm{x})$; D, gerbera daisy $(40,000 \mathrm{X})$; and E, zinnia

172 (53,000x). Filaments in B, C and D were partially purified and the filaments in A and E were 173 further purified by centrifugation on a $\mathrm{CsCl}$-sucrose gradient. The filaments were stained with $1742 \%$ phosphotungstic acid.

\begin{tabular}{|l|r|r|r|r|r|}
\hline & chrysanthemum & coneflower & gerbera & sunflower & zinnia \\
\hline Mean & 8.57 & 8.94 & 7.64 & 8.91 & 8.39 \\
\hline SD & 1.16 & 0.98 & 0.92 & 0.88 & 1.01 \\
\hline Min & 6.38 & 7.05 & 6.10 & 7.41 & 6.72 \\
\hline Max & 10.47 & 10.63 & 9.69 & 10.70 & 10.41 \\
\hline
\end{tabular}

176 Table 1 Filament diameter obtained by measuring 50 filaments each from coneflower, gerbera,

177 chrysanthemum, sunflower, and zinnia. 

molecular mass between 20 and $25 \mathrm{kDa}$. Each preparation contained proteins with other molecular masses that were variably present in the different preparations. For example, the

$182 \approx 10 \mathrm{kDa}$ and $\approx 60 \mathrm{kDa}$ proteins present in the preparation shown in Figure $2 \mathrm{~B}$ are far less

183 abundant or absent from the preparations shown in Figure 2A.

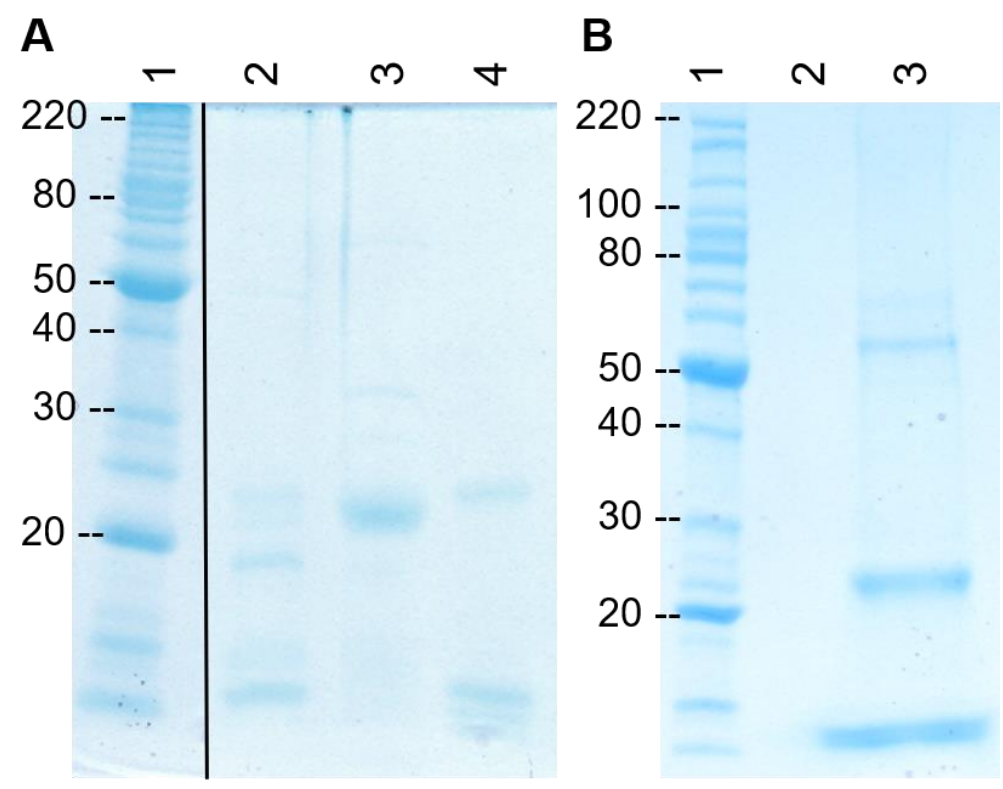

185 Figure 2. Proteins of filaments purified on cesium sucrose gradients were examined by SDS-

186 PAGE. A, proteins of filaments from sunflower (lane 2), gerbera (lane 3), and zinnia (lane 4). B, 187 proteins from a different filament preparation than shown in A from gerbera (lane 3). No sample was loaded in lane 2. filament preparations from chrysanthemum, gerbera, and zinnia (Figure 3). The peptide sequences obtained were identical within a species and nearly-identical between the species

193 (Table 2). A tBLASTn search of the EST sequences from chrysanthemum (taxid: 13422) in

194 GenBank revealed that the N-terminal sequences had 100\% identity (chrysanthemum 13/13 AA,

195 zinnia 12/12 AA), or nearly perfect identity (gerbera, 88\% 15/17 AA and 93\% positive, 16/17

196 AA), with predicted N-terminus of mature kunitz-type protease inhibitors (KTI) from

197 chrysanthemum (accession numbers DK939406.1) suggesting that filaments are composed of 198 mature KTI. 
To test this hypothesis, we decided to sequence sunflower filament proteins using collision-induced dissociation tandem mass spectrometry (CID MS/MS). At the time we did this the sunflower genome was not yet available and there was no complete cDNA sequence for the KTI most closely related to the chrysanthemum sequence. Therefore, we cloned and sequenced the complete coding region of the related sunflower KTI. The 678 bp product was deposited in GenBank as accession number KY039997.01. The translated amino acid sequence was classified as an STI domain-containing protein (domain architecture ID 11087211) with specific hits to Kunitz_legume (pfam00197) and the STI superfamily (cl11466) proteins. The AA sequence was

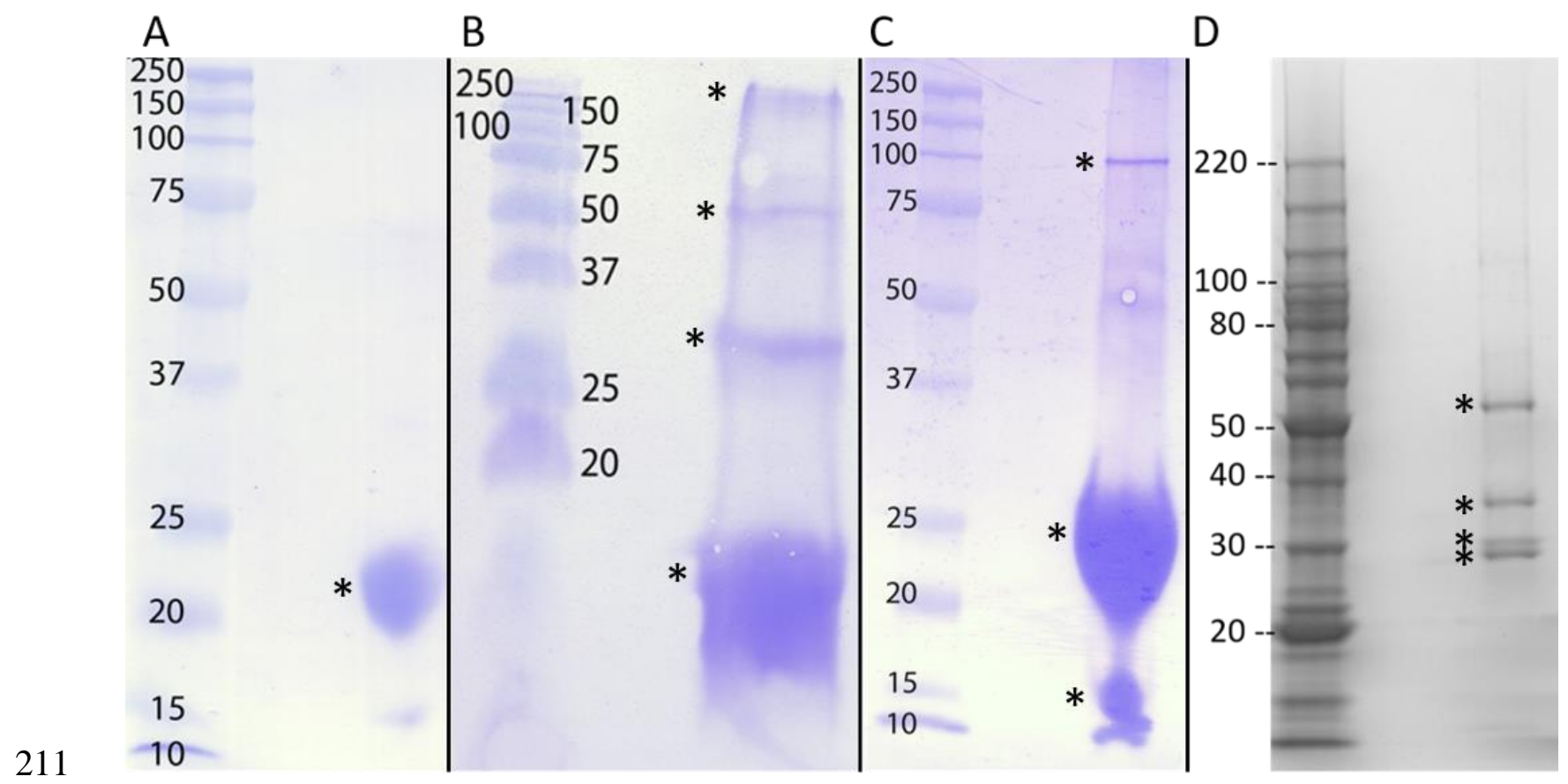

212 Figure 3. SDS-PAGE of proteins in filament preparations that were sequenced by Edman

213 degradation (A-C) or CID MS/MS (D). The preparations are from gerbera (A), zinnia (B),

214 chrysanthemum (C) or sunflower (D). The bands marked with a * were sequenced. 


\begin{tabular}{|c|c|c|c|c|c|}
\hline \multicolumn{6}{|c|}{ N-Terminal protein sequencing results } \\
\hline & & Plan & chrysanthemum & gerbera & zinnia \\
\hline \multirow{8}{*}{ 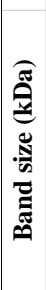 } & 12 & Major & ADVIYD $\overline{\left(S+S^{\prime}\right) \text { AGNKLL }}$ & & ADVIYD $\left(S+S^{\prime}\right)$ AGNKL \\
\hline & & Minor & GFK $\left(S+S^{\prime}\right)$ ATIGNE $\left(S+S^{\prime}\right)$ NR & & $\operatorname{VIYD}\left(\mathrm{S}+\mathrm{S}^{\prime}\right) \mathrm{K}(\mathrm{G} / \mathrm{V})(\mathrm{N} / \mathrm{V}) \mathrm{KLLR}$ \\
\hline & 22 & Major & ADVIYD (S+S ' ) AGNKLL & $\left(S+S^{\prime}\right)$ DVIYD (S+S ') DGNKLL (S+S ') GVP & ADVIYD (S+S ') AGNKL \\
\hline & & Minor & & $\left(S+S^{\prime}\right)$ DVIYD $\left(S+S^{\prime}\right)$ DGNKLL $\left(S+S^{\prime}\right)(R / T)$ VNT & \\
\hline & 55 & Major & & & ADVIYDSAGNKL \\
\hline & & Minor & & & SDVIYDSAGNKL \\
\hline & 100 & Major & & & ADVIYDSAGNKL \\
\hline & & Minor & & & VIYDSKGNKLLL \\
\hline
\end{tabular}

218 Table 2. N-terminal protein sequencing results for the proteins observed by SDS-PAGE from 219 purified filaments.

Sunflower filament proteins were resolved by SDS-PAGE and the four proteins marked

222 in Figure 3D were cut out of the gel, digested with trypsin, and sequences of the resulting

223 peptides were obtained by CID MS/MS analysis and compared to the sunflower KTI sequence

224 (Figures 4 and 5, and supplementary Figures 1-4). The top sequence hit from each of the trypsin

225 fragments had $100 \%$ identity with predicted fragments from the cloned sunflower KTI

226 supporting that the sunflower filaments are composed of KTI. None of the sequences mapped to 227 the signal sequence supporting the hypothesis that filaments are composed of the mature protein. 


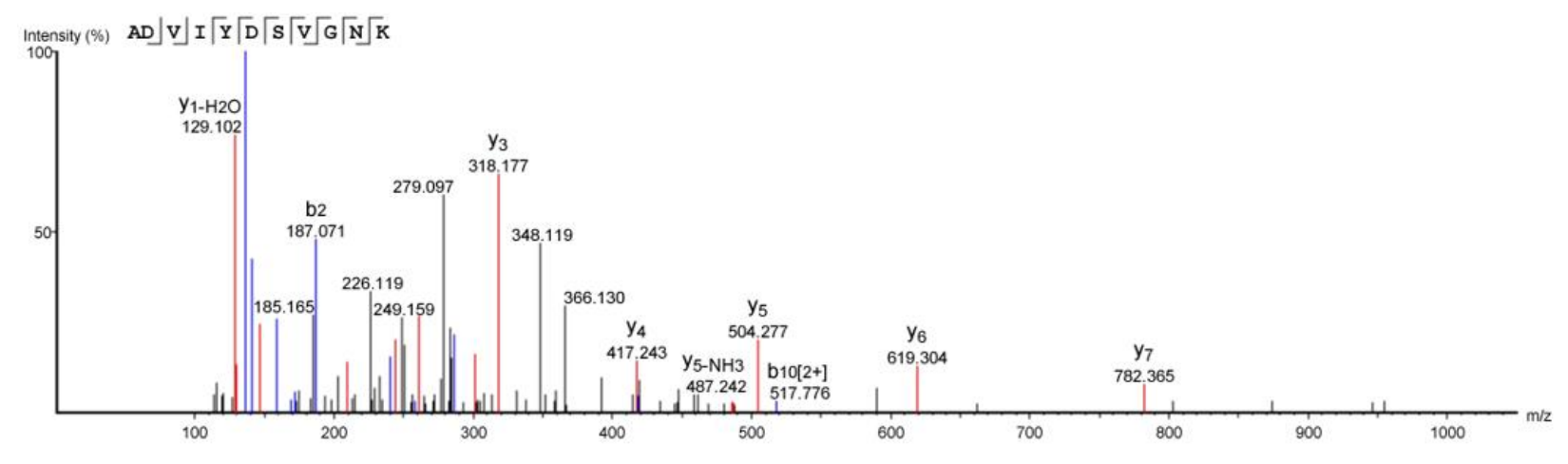

\begin{tabular}{|c|c|c|c|c|c|c|c|c|c|c|}
\hline$\#$ & b & $\mathrm{b}-\mathrm{H} 2 \mathrm{O}$ & b-NH3 & b $(2+)$ & Seq & $y$ & $y-\mathrm{H} 2 \mathrm{O}$ & $y-\mathrm{NH} 3$ & $y(2+)$ & $\#$ \\
\hline 1 & 72.04 & 54.03 & 55.02 & 36.52 & A & & & & & 11 \\
\hline 2 & 187.07 & 169.10 & 170.04 & 94.04 & D & 1109.55 & 1091.54 & 1092.52 & 555.27 & 10 \\
\hline 3 & 286.14 & 268.13 & 269.11 & 143.57 & V & 994.52 & 976.51 & 977.49 & 497.76 & 9 \\
\hline 4 & 399.22 & 381.21 & 382.20 & 200.11 & I & 895.45 & 877.44 & 878.42 & 448.23 & 8 \\
\hline 5 & 562.29 & 544.28 & 545.26 & 281.64 & $Y$ & 782.36 & 764.36 & 765.34 & 391.68 & 7 \\
\hline 6 & 677.31 & 659.30 & 660.29 & 339.16 & $\mathrm{D}$ & 619.30 & 601.29 & 602.28 & 310.15 & 6 \\
\hline 7 & 764.35 & 746.34 & 747.32 & 382.67 & S & 504.28 & 486.27 & 487.24 & 252.64 & 5 \\
\hline 8 & 863.42 & 845.40 & 846.39 & 432.21 & V & 417.24 & 399.24 & 400.22 & 209.09 & 4 \\
\hline 9 & 920.44 & 902.43 & 903.41 & 460.72 & $\mathrm{G}$ & 318.18 & 300.17 & 301.15 & 159.59 & 3 \\
\hline 10 & 1034,48 & 1016.47 & 1017.45 & 517.78 & $\mathrm{~N}$ & 261.16 & 243.15 & 244.13 & 131.08 & 2 \\
\hline 11 & & & & & K & 147.11 & 129.10 & 130.09 & 74.06 & 1 \\
\hline
\end{tabular}

231 Figure 4. Tandem mass spectra and ion series for the peptide ADVIYDSVGNK from the smallest sunflower protein of $\approx 28 \mathrm{kDa}$. The table show the predicted ions. The $\mathrm{b}$ and $\mathrm{y}$ ions 233 present in the spectrum are in blue and red, respectively.

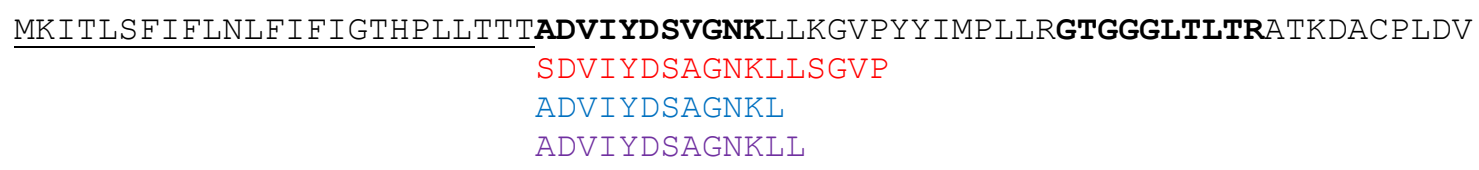

245 Figure 5. The N-terminal sequences of gerbera (red, top), zinnia, (blue, middle) and 246 chrysanthemum (purple, bottom) filament protein aligned with the sunflower KTI sequence 247 (KY039997) (black). The predicted signal sequence is underlined and the peptides identified by 248 CID MS/MS are in bold. Note that consistent with the protein being the mature sunflower KTI, 249 the first sunflower sequence begins at the predicted signal sequence cleave site rather than a 250 trypsin site. 
Several KTIs are glycoproteins (Ee et al. 2009). Therefore, we used glycostaining to determine if gerbera filament proteins were glycosylated (Figure 6). This staining showed that the major $22 \mathrm{kDa}$ protein and a smaller $\approx 10 \mathrm{kDa}$ protein were glycosylated.

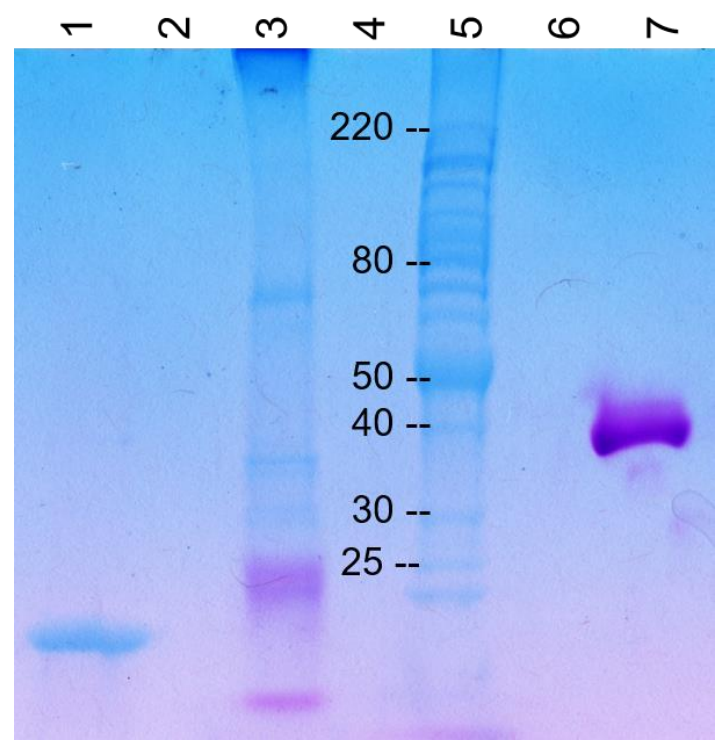

Figure 6. The major gerbera filament protein is glycosylated. Filament proteins were subjected to SDS PAGE and stained to detect glycoproteins. Lane 1 contains purified tobacco mosaic virus as a negative control, lane 3 purified gerbera filaments, lane 5 Benchmark $^{\mathrm{TM}}$ protein ladder, lane 7 horseradish peroxidase as a positive control provided with the kit. No samples were loaded into 259 lanes $2,4,6$.

\section{Discussion}

In the course of searching for plant viruses in members of the Asteraceae filamentous structures were identified. Filaments extracted from chrysanthemum (Chrysanthemum spp.), coneflower (Echinacea spp.), gerbera (Gerbera jamesonii, G. hybrida), sunflower (Helianthus annuus), and zinnia (Zinnia hybrida) had mean diameters ranging from 7.6 to $8.9 \mathrm{~nm}$ and were of variable length ranging up to several thousand $\mathrm{nm}$. These filaments are not similar to virions of known plant viruses and we were not able to identify any associated virus nucleic acid. Therefore, we decided to characterize the filament proteins.

When subjected to SDS-PAGE the filament preparations from chrysanthemum, gerbera, sunflower and zinnia contained several proteins. The initial $\mathrm{N}$-terminal protein sequencing of major filament associated proteins from three species (gerbera, zinnia, chrysanthemum) all yielded nearly the same sequence, which matched a predicted mature KTI sequence from

273 chrysanthemum. The nearly identical $\mathrm{N}$-terminal sequence from three different species indicates 274 the filamentous forming protein may be conserved across Asteraceae. The predicted size of the 
mature sunflower KTI is $21.5 \mathrm{kDa}$, which corresponds well to the size of the most abundant protein in each filament preparation. Based on these results we believe that the filaments are composed of the mature KTI and that the other proteins present in the filaments are KTI breakdown products or KTI aggregates. This hypothesis is supported by the fact that the abundance of many of these proteins relative to the mature KTI varied between filament preparations. This effect may be observed with the preparations from zinnia which in one experiment yielded proteins of $<10$ and $22 \mathrm{kDa}$ while another experiment yielded proteins of $<10,22$, and $55 \mathrm{kDa}$ (Fig 1 A-lane 3 and B-lane 3). In addition, the sequence of proteins larger than mature KTI from zinnia (Table 2) and sunflower (supplemental Figures 1-4) indicated they were KTI.

We cloned and sequenced a sunflower gene with high similarity to chrysanthemum KTI and compared the predicted protein sequence to the major filament proteins of sunflower fibril as determined by CID MS/MS. The sequence of four of the trypsin fragments, that were present in each of the protein bands sequenced, had $100 \%$ identity with the translated, sunflower KTI and covers $25 \%$ of the total sequence (51 out of 200 amino acids). The presence of KTI filaments in the four species examined suggest that these filaments may occur in all or many of the Asteraceae.

Several KTIs are glycoproteins (Ee et al. 2009, Paiva et al. 2003, Macedo et al. 2003, Azarkan et al. 2006, do Soccoro et al. 2002) and KTI in filaments was glycosylated. This suggests that filaments form from the mature KTI after it has exited the secretory pathway, perhaps in the protein bodies.

Although not widely studied, proteins and enzymes from animals, fungi and plants are known to assemble into filaments (Park \& Horton 2019). Assembly into filaments can change the enzymatic properties (Park \& Horton 2019). In plants $\beta$-glucosidase, ribonucleotide reductase, and IRE1 form filaments (Park \& Horton 2019). This raises the question does KTI exist both in both filamentous and non-filamentous forms and are the properties of the two forms different? An alternative is that forming filaments is a way to pack KTI in protein bodies. Since KTI are involved in defense against herbivory it is also possible that filament formation is important to the activity or stability of the filaments in the herbivore.

Another question that should be addressed is if the filaments have a function in plants. We identified filaments in plants showing "disease symptoms" including flower doubling and leaf curling and distortion and have noted that the abundance of filaments was highly variable. Plants without visible symptoms can contain very low, and sometimes undetectable levels of filaments. Interestingly, some KTIs have demonstrated roles in leaf shape, shoot growth and root growth (Islam et al 2015; Li et al 2008). Further studies are needed to determine if filament

\section{Accession Numbers}

Sequence data from this article can be found in GenBank under accession number 
Supplementary Data files

316

Supplementary Figures

\section{Acknowledgements}

HATCH/MAES projects MIN -071-019 and MIN-71-041, Fred C. Gloeckner Foundation Inc., MnDRIVE Global Food Initiative, University of Minnesota Doctoral Dissertation Fellowship,

\section{Conflict of Interest Statement}

324 The authors have no conflicts of interest to declare.

\section{Author Contributions}

327 SAB- designed the research; performed research; analyzed data; wrote the paper

328 NEO- designed the research; performed research; analyzed data; wrote the paper

329 BEL- designed the research; performed research; analyzed data; edited the paper

\section{$331 \quad$ Citations}

332 Azarkan, M., Dibiani, R., Goormaghtigh, E., Raussens, V., \& Baeyens-Volant, D. (2006). The 333 papaya Kunitz-type trypsin inhibitor is a highly stable $\beta$-sheet glycoprotein. Biochimica et 334 Biophysica Acta (BBA)-Proteins and Proteomics, 1764(6), 1063-1072.

335 Badouin, H., Gouzy, J., Grassa, C. J., Murat, F., Staton, S. E., Cottret, L., ... \& Legrand, L. 336 (2017). The sunflower genome provides insights into oil metabolism, flowering and Asterid 337 evolution. Nature, 546(7656), 148-152.

338 Brandle, J. E., Starratt, A. N., \& Gijzen, M. (1998). Stevia rebaudiana: its agricultural, 339 biological, and chemical properties. Canadian journal of plant science, 78(4), 527-536.

340 Casida, J. E. (1980). Pyrethrum flowers and pyrethroid insecticides. Environmental health 341 perspectives, 34, 189.

342 Dahlin, J. L., Nissink, J. W. M., Strasser, J. M., Francis, S., Higgins, L., Zhou, H., ... \& Walters, 343 M. A. (2015). PAINS in the assay: chemical mechanisms of assay interference and promiscuous 344 enzymatic inhibition observed during a sulfhydryl-scavenging HTS. Journal of medicinal 345 chemistry, 58(5), 2091-2113. 
de Souza Cândido, E., Pinto, M. F. S., Pelegrini, P. B., Lima, T. B., Silva, O. N., Pogue, R., ... \& Franco, O. L. (2011). Plant storage proteins with antimicrobial activity: novel insights into plant defense mechanisms. The FASEB Journal, 25(10), 3290-3305.

do Socorro, M.; Cavalcanti, M.; Oliva,M. L.; Fritz, H.; Jochum, M.; Mentele, R.; Sampaio, M.; Batista, I. F.; Sampaio, C. A. Characterization of a Kunitz trypsin inhibitor with one disulfide bridge purified from Swatzia pickellii. Biochem. Biophys. Res. Commun. 2002, 291, 635-639.

Ee, K. Y., Zhao, J., Rehman, A. U., \& Agboola, S. O. (2009). Purification and characterization of a Kunitz-type trypsin inhibitor from Acacia victoriae Bentham seeds. Journal of agricultural and food chemistry, 57(15), 7022-7029. inhibitory functions of potato tuber proteinaceous inhibitors. Mol Genet Genomics 290, 387-398.

Glaczinski, H., Heibges, A., Salamini, R., and Gebhardt, C. (2002). Members of the Kunitz-type protease inhibitor gene family of potato inhibit soluble tuber invertase in vitro. Potato Res 45 , 163-176.

Gunning, B. E. S. (1965). The fine structure of chloroplast stroma following aldehyde osmiumtetroxide fixation. The Journal of cell biology, 24(1), 79-93.

Heibges, A., Salamini, F., and Gebhardt, C. (2003). Functional comparison of homologous members of three groups of Kunitz-type enzyme inhibitors from potato tubers (Solanum tuberosum L.). Mol Genet Genomics 269, 535-541.

Islam, A., Leung, S., Burgess, E.P., Laing, W.A., Richardson, K.A., Hofmann, R.W., Dijkwel, P.P., and McManus, M.T. (2015). Knock-down of transcript abundance of a family of Kunitz proteinase inhibitor genes in white clover (Trifolium repens) reveals a redundancy and diversity of gene function. New Phytol 208, 1188-1201.

Jeffrey, C. 2007. Compositae: Introduction with key to tribes. Pages 61-87 in Families and Genera of Vascular Plants, vol. VIII, Flowering Plants, Eudicots, Asterales (J. W. Kadereit and C. Jeffrey, eds.). Springer-Verlag, Berlin type proteinase inhibitor is induced in response to abscisic acid, ethylene, methyl jasmonate, and water deficit. Molecules and Cells 13, 144-147. related genes of rubber particles and latex in fig tree (Ficus carica) and their expressions by abiotic stress or plant hormone treatments. Plant Cell Physiol 44, 412-414. 
380 Lin-Moshier, Y., Sebastian, P. J., Higgins, L., Sampson, N. D., Hewitt, J. E., \& Marchant, J. S.

381 (2013). Re-evaluation of the role of calcium homeostasis endoplasmic reticulum protein

382 (CHERP) in cellular calcium signaling. Journal of Biological Chemistry, 288(1), 355-367.

383 Ma, B., Zhang, K., Hendrie, C., Liang, C., Li, M., Doherty-Kirby, A., \& Lajoie, G. (2003).

384 PEAKS: powerful software for peptide de novo sequencing by tandem mass spectrometry. Rapid 385 communications in mass spectrometry, 17(20), 2337-2342.

386 Macedo, M. L. R., Freire, M. D. G. M., Cabrini, E. C., Toyama, M. H., Novello, J. C., \& 387 Marangoni, S. (2003). A trypsin inhibitor from Peltophorum dubium seeds active against pest 388 proteases and its effect on the survival of Anagasta kuehniella (Lepidoptera: Pyralidae).

389 Biochimica et Biophysica Acta (BBA)-General Subjects, 1621(2), 170-182.

390 Muntz, K. (1998) Deposition of storage proteins. Plant Mol. Biol. 38, 77-99

391 Park, C. K., \& Horton, N. C. (2019). Structures, functions, and mechanisms of filament forming 392 enzymes: a renaissance of enzyme filamentation. Biophysical reviews, vol 11, 927-994.

393 Paiva, P. M. G., Souza, A. F., Oliva, M. L. V., Kennedy, J. F., Cavalcanti, M. S. M., Coelho, L.

394 C. B. B., \& Sampaio, C. A. M. (2003). Isolation of a trypsin inhibitor from Echinodorus

395 paniculatus seeds by affinity chromatography on immobilized Cratylia mollis isolectins.

396 Bioresource Technology, 88(1), 75-79.

397 Rappsilber, J., Ishihama, Y., \& Mann, M. (2003). Stop and go extraction tips for matrix-assisted 398 laser desorption/ionization, nanoelectrospray, and LC/MS sample pretreatment in proteomics.

399 Analytical chemistry, 75(3), 663-670.

400 Schindelin, J., Arganda-Carreras, I., Frise, E., Kaynig, V., Longair, M., Pietzsch, T., ... \&

401 Cardona, A. (2012). Fiji: an open-source platform for biological-image analysis. Nature methods, 402 9(7), 676-682.

403 Shevchenko, A., Wilm, M., Vorm, O., \& Mann, M. (1996). Mass spectrometric sequencing of 404 proteins from silver-stained polyacrylamide gels. Analytical chemistry, 68(5), 850-858. 